\title{
STUDI KEANEKARAGAMAN IKAN YANG TERTANGKAP MENGGUNAKAN ATRIBUT RUMPON BERBEDA DI SUNGAI MENTENANG KABUPATEN MERANGIN
}

\author{
Renda Preniti $^{1}$, Syafrialdi ${ }^{2}$, Djunaidi $^{3}$ \\ 1 Mahasiswa Program Studi Pemanfaatan Sumberdaya Perikanan \\ 2 dan 3 Pengajar Pada Program Studi Pemanfaatan Sumberdaya Perikanan \\ Universitas Muara Bungo
}

\begin{abstract}
ABSTRAK
Penelitian ini dilakukan di Sungai Mentenang Kecamatan Jangkat Kabupaten Merangin dan penelitian ini dilaksanakan dari bulan Januari 2018 sampai bulan April 2018. Tujuan penelitian adalah untuk mengetahui tingkat keanekaragaman jenis ikan dari penggunaan rumpon dengan atribut yang berbeda di perairan Sungai Mentenang Kabupaten Merangin serta untuk mengetahui Atribut Rumpon yang mana yang lebih disukai oleh ikan di Perairan Sungai Mentenang Kabupaten Merangin.

Dari hasil penelitian menunjukkan bahwa Keanekaragaman jenis Ikan yang tertinggi di temukan pada rumpon yang menggukan atribut Ranting Kayu, yaitu sebanyak 32 ekor dengan indeks keanekaragaman sebesar 0,3281 dan indeks keseragaman sebesar 0,950 yang terdiri dari 8 jenis ikan di Stasiun I dan di Stasiun II 6 jenis ikan diantaranya: Ikan Nalis (Labiobarbus lineatus), Senggiring, (Mystus nigreceps), Sebarau (Hampala macrolepidota) Bentulu (Barbichthys laevis) Semah (Tor soro) Tana (Barbodes binotatus) Puyou (Osteochilus waandersii) dan Kepyur (Barbodes lateristiga). Atribut rumpon yang disukai oleh ikan yaitu menggunakan atribut rumpon Ranting Kayu dengan jumlah hasil tangkapan terbanyak dengan jumlah 8 jenis ikan dengan jumlah individu sebanyak 32 individu. Sedangkan pada atribut rumpon daun kelapa memperoleh tangkapan 6 jenis dengan jumlah 11 ekor dan diikuti oleh atribut lainnya.
\end{abstract}

\section{Kata kunci : Keanekaragaman, Jenis Ikan, Rumpon Dan Sungai}

\section{PENDAHULUAN}

Penggunaan teknologi rumpon yang tepat dapat meningkatkan hasil tangkapan, menghemat bahan bakar, dan menghemat umpan. Subani (1986) mengemukakan bahwa ikan-ikan yang berkumpul disekitar rumpon menggunakan rumpon sebagai tempat berlindung juga untuk mencari makan dalam arti luas tetapi tidak memakan daun-daun rumpon tersebut.

Wilayah Kabupaten Merangin, banyak dialiri sejumlah sungai baik sungai kecil, sedang dan besar di 
SEMAH : Journal Pengelolaan Sumberdaya Perairan VOL. 3 No. 1

April 2019

berbagai penjuru. Berdasarkan data status lingkungan lingkungan hidup daerah provinsi Jambi (2014) Sungai Mentenang memliki panjang $15 \mathrm{~km}$ dengan kedalaman $5 \mathrm{~m}$ dan merupakan sungai kelas 2 .

Berdasarkan survei yang telah dilakukan Sungai Mentenang memeliki panjang $\pm 15 \mathrm{Km}$ dan lebar \pm 4-7 $\mathrm{m}$ dan kedalam $\pm 5 \mathrm{~m}$, dibagian hulu memiliki tipe ekologi perairan berarus deras sampai sedang dan umumnya berbatu, dikeliling sungai merupakan daerah persawahan dan perkebunan.

$$
\text { Dalam rangka meningkatkan }
$$

keragaman ikan disuatu perairan, diperlukan alat bantu yang dapat mengumpulan ikan dengan menciptakan tempat bernaung bagi ikan, dengan membuat rumpon untuk langkah konservasi atau penciptakan plasma nuftah dari rumpon yang berasal dari bahan disekitar lingkungan. Untuk itu kegiatan tentang keanekaragaman ikan di pengaruhi atribut rumpon penting untuk dilakukan sehingga data ini dapat digunakan untuk mengukur sumberdaya perikanan.

Tujuan yang ingin dicapai dalam penelitian ini adalah :

Untuk mengetahui tingkat keanekaragaman jenis ikan dari penggunaan rumpon dengan atribut yang berbeda di
ojs.umb-bungo.ac.id/index-php/SEMAHJPSP ISSN : 2580-0736

perairan Sungai Mentenang Kabupaten Merangin.

Untuk mengetahui atribut rumpon yang mana yang lebih disukai oleh ikan di perairan Sungai Mentenang Kabupaten Merangin.

\section{METODOLOGI PENELITIAN}

Penelitian ini dilaksanakan dari bulan April - Oktober 2018. Sampel diambil dan ditangkap sebanyak mungkin di masing-masing stasiun dengan menggunakan atribut rumpon berbeda. Sampel di identifikasi di Laboratorium Fakultas Perikanan. Peta lokasi penelitian dapat dilihat pada Gambar 3.1.

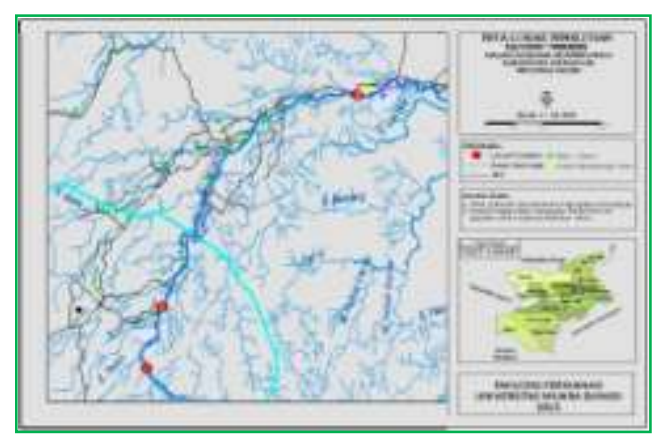

Gambar 3.1 Peta Lokasi Penelitian

Metode yang digunakan dalam penelitian ini adalah eksperimen fishing, yaitu mengoperasikan rumpon dengan meletakkan 3 atribut rumpon secara acak dalam satu tempat selama 30 hari dengan jarak antar rumpon $\pm 10 \mathrm{~m}$. 
SEMAH : Journal Pengelolaan Sumberdaya Perairan VOL. 3 No. 1

April 2019

Sampel dikoleksi dari Sungai Mentenang dengan alat tangkap jala tebar dan pukat di titik lokasi yang berbeda. Sampel ikan yang tertangkap diawetkan dalam formalin $4 \%$ dan sebelum di Identifikasi diganti dengan alcohol $70 \%$, ikan diidentifikasi dengan menggunakan buku Kotellat, et al 1993.

Untuk menganalisis data yang diperoleh dari dilapangan digunakan beberapa metoda analisis yaitu Analisis Indeks Keanekaragaman Jenis Ikan $\left(H^{*}\right)$,Kepadatan Populasi, Kepadatan Relatif dan Frekuensi Kehadiran

\section{HASIL DAN PEMBAHASAN}

1. Jenis Ikan Yang Tetangkap Berdasarkan Atribut Rumpon

Hasil ikan yang tertangkap tersebut baik jumlah ataupun jenis ikan yang berbeda. Masing-masing rumpon yang digunakan untuk lebih jelasnya dapat dilihat tabel 4.1.

Berdasarkan tabel 4.1 perbedaan jenis dan jumlah individu berdasarkan atribut rumpon yang digunakan berbeda karena kesukaan ikan terhadap rumpon tidak sama. berikut penjelasan masing- masing hasil tangkapan berdasarkan atribut rumpon yang digunakan :

Hasil penelitian menggunakan atribut rumpon daun kelapa menunjukkan jumlah
ojs.umb-bungo.ac.id/index-php/SEMAHJPSP ISSN : 2580-0736

\begin{abstract}
hasil tangkapan di dua Stasiun penangkapan di Perairan Sungai Mentenang Kecamatan Jangkat, tertangkap sebanyak 22 ekor yang terdiri dari 6 jenis ikan pada Stasiun I dan 4 jenis ikan pada stasiun II dengan jumlah individu sebanyak 11 individu .
\end{abstract} Sedangkan untuk atribut rumpon Ranting kayu menunjukkan bahwa hasil tangkapan di 2 stasiun penangkapan di Perairan Sungai Mentenang Kecamatan Jangkat, ikan yang tertangkap sebanyak 31 ekor yang terdiri dari 8 jenis ikan pada Stasiun I dengan jumlah individu 22 jenis sedangkan di Stasiun II terdapat 6 jenis dengan individu sebanyak 10 individu dan untuk Hasil penelitian menggunakan atribut rumpon Pelepah daun Kopi menunjukkan bahwa hasil tangkapan di 2 Stasiun penangkapan di Perairan Sungai Mentenang Kecamatan 


\begin{tabular}{|c|c|c|c|c|c|c|c|c|c|}
\hline \multirow{2}{*}{ No } & \multirow[b]{2}{*}{ Spesies } & \multicolumn{6}{|c|}{ Atribut Rumpon } & \multirow{3}{*}{$\begin{array}{r}\text { Jumlah/ } \\
\text { - Individu }\end{array}$} & \multirow{3}{*}{$\begin{array}{l}\text { terseb } \\
\text { ut di }\end{array}$} \\
\hline & & \multicolumn{2}{|c|}{ Daun Kelapa } & \multicolumn{2}{|c|}{ Ranting Kayu } & \multicolumn{2}{|c|}{ Daun Kopi } & & \\
\hline & & $\begin{array}{l}\text { Stasiun } \\
\text { I }\end{array}$ & $\begin{array}{l}\text { Stasiun } \\
\text { II }\end{array}$ & $\begin{array}{l}\text { Stasiun } \\
\text { I }\end{array}$ & $\begin{array}{l}\text { Stasiun } \\
\text { II }\end{array}$ & $\begin{array}{c}\text { Stasiun } \\
\text { I }\end{array}$ & $\begin{array}{c}\text { Stasiu } \\
\text { n II }\end{array}$ & & \\
\hline 1 & Labiobarbus lineatus & 2 & 1 & 3 & 2 & 1 & 2 & 11 & \\
\hline 2 & Mystus nigreceps & 2 & 4 & 3 & 1 & - & - & 10 & ba \\
\hline 3 & Hampala macrolipidota & 1 & - & 3 & 2 & - & - & 6 & \\
\hline 4 & Barbichthys laevis & 1 & 3 & 1 & - & 1 & - & 6 & \\
\hline 5 & Tor soro & - & - & 3 & 1 & - & - & 4 & isa \\
\hline 6 & TBarbodes binotatus & 3 & - & 5 & 2 & 2 & 1 & 13 & $n$ \\
\hline 7 & Osteochilus waandersii & 2 & 3 & 1 & - & 1 & - & 7 & \\
\hline 8 & Barbodes lateristiga & - & - & 3 & 2 & - & 2 & 7 & \\
\hline Juml: & ah Total & & & & & & & 64 & Indek \\
\hline
\end{tabular}

Jangkat, ikan yang tertangkap sebanyak 10 ekor yang terdiri dari 5 jenis ikan.

Keanekaragaman jenis Ikan yang tertinggi di temukan pada rumpon yang menggukan atribut ranting kayu, yaitu sebanyak 32 ekor ikan yang terdiri dari 8 jenis ikan pada Stasiun I dan Stasiun II sebanyak 6 jenis. Sesuai dengan pernyataan Ross dalam Jukri (2013:34), bahwa keanekaragaman dan kelimpahan ikan juga ditentukan oleh karakteristik habitat perairan.

\section{Nilai Keanekaragaman Jenis Ikan (Hi)}

Nilai indeks Keanekaragaman Jenis Ikan (Hi) yang tertangkap selama penelitian di 2 Stasiun menggunakan 3 atribut rumpon yang berbeda di Perairan Sungai

Mentenang Kecamatan Jangkat. berdasarkan Indeks Shannon dapat dilihat pada Tabel 4.2. Berdasarkan hasil perhitungan nilai Indeks Keanekaragaman pada Tabel Tabel 4.2 s Keanekaragaman jenis ikan (Hi) yang tertangkap selama penelitian di 2 Stasiun Perairan Sungai Mentenang Kecamatan Jangkat dengan perlakuan menggunakan 3 atribut rumpon yang berbeda dimana Indeks tertinggi ditemui pada rumpon dengan atribut ranting kayu dengan nilai indeks (Hi) 0,3281.

Berdasarkan tabel diatas dapat dibuat sebuah indeks keanekaragaman untuk melihat stabilitas suatu komunitas atau menunjukkan kondisi struktur suatu komunitas dari keanekargaman jenis 


\begin{tabular}{|c|c|c|c|c|c|c|c|}
\hline \multirow{4}{*}{ No } & \multirow{4}{*}{ Tanggal } & \multicolumn{6}{|c|}{ Nilai Indeks Keanekaragaman (Hi) } \\
\hline & & \multirow{2}{*}{\multicolumn{2}{|c|}{$\begin{array}{c}\begin{array}{c}\text { Atribut } \\
\text { Rumpon }\end{array} \\
\text { Daun Kelapa }\end{array}$}} & \multirow{2}{*}{\multicolumn{2}{|c|}{$\begin{array}{c}\begin{array}{c}\text { Atribut } \\
\text { Rumpon }\end{array} \\
\text { Ranting } \\
\text { Kayu }\end{array}$}} & \multirow{2}{*}{\multicolumn{2}{|c|}{$\begin{array}{c}\begin{array}{r}\text { Atribut } \\
\text { Rumpon }\end{array} \\
\text { Daun Kopi }\end{array}$}} \\
\hline & & & & & & & \\
\hline & & ST I & ST II & ST I & ST II & ST I & ST II \\
\hline \multirow[t]{2}{*}{$\mathrm{I}$} & 24 April 2018 & & & & & & \\
\hline & Nilai Indeks (Hi) & 0,1875 & 0,1718 & 0,3281 & 0,1562 & 0,0781 & 0,0625 \\
\hline \multirow[t]{2}{*}{ I } & Nilai Indeks & & & & & & \\
\hline & Keseragaman (E) & & & & & & \\
\hline 11 & & 0,292 & 0,268 & 0,950 & 0,244 & 0,122 & 0,097 \\
\hline
\end{tabular}

orgasme yang terdapat dalam suatu area. Nilai rata - rata indeks keanekaragaman jenis ikan di Sungai Mentenang Kecaman Jangkat di sajikan pada pada gambar 4.1.

Berdasarkan indeks keragaman diatas yang merupakan hasil dari rumus Shanon Wiener maka dapat dinyatakan : kondisi ekosistem tidak seimbang dan tekanan ekologis rendah.

Rumpon Ranting Kayu pada Stasiun I dan Stasiun II dengan nilai indeks $H^{\prime}=0,3281$ dan 0,1562 nits/ind termasuk dalam keanekaragaman rendah serta memiliki produktifitas yang rendah,

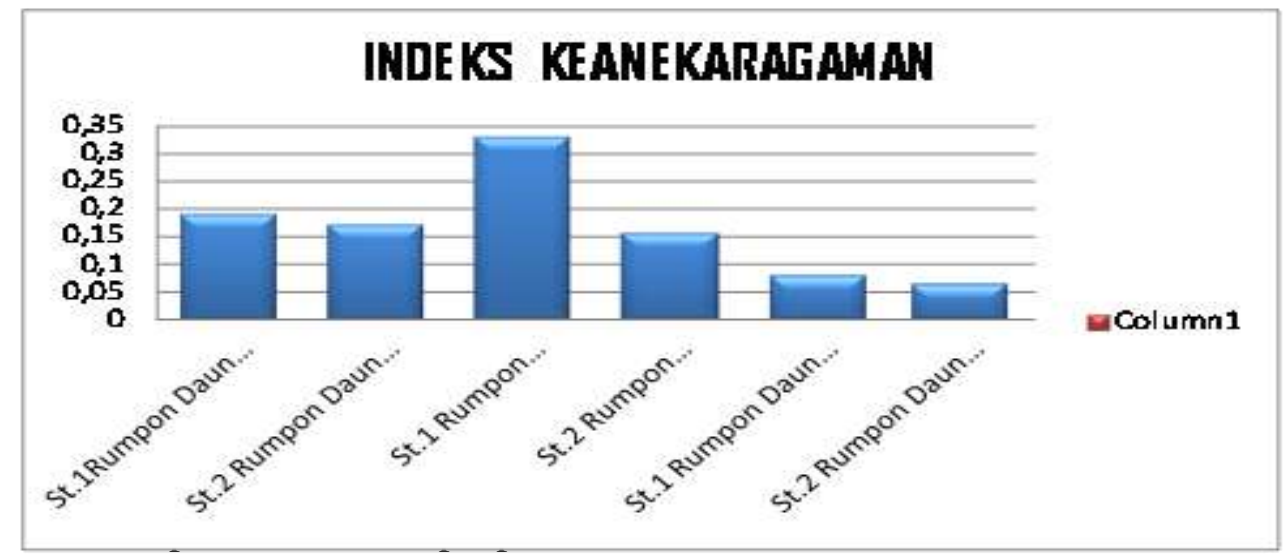

dan Stasiun II dengan nilai indeks $\mathrm{H}^{\prime}=$

0,1875 dan 0,1718 nits/ind termasuk dalam keanekaragaman rendah serta memiliki produktifitas yang rendah, kondisi ekosistem tidak seimbang dan tekanan ekologis rendah meskipun indeks keanekaragaman atribut rumpon ranting kayu merupakan indeks tertinggi 
SEMAH : Journal Pengelolaan Sumberdaya Perairan VOL. 3 No. 1

April 2019

jika dibandingkan dengan indeks keanekaragaman pada atribut rumpon lainnya.

Rumpon Daun Kopi pada Stasiun I dan Stasiun II dengan nilai indeks $H^{\prime}=0,0781$ dan 0,0625 nits/ind termasuk dalam keanekaragaman cukup rendah serta memiliki produktifitas yang cukup rendah, kondisi ekosistem cukup rendah dan tekanan ekologis rendah.

\section{Indeks Keseragaman}

Kriteria nilai keseragaman, jika E mendekati 0 maka kemerataan antara spesies rendah, dan jika $\mathrm{E}$ mendekati 1 maka kemerataan antara spesies relatif merata atau jumlah individu masing-masing spesies relatif sama (Jukri dkk, (2013). Indek keseragaman dapat dilihat pada tabel 4.3
ojs.umb-bungo.ac.id/index-php/SEMAHJPSP ISSN : 2580-0736

\begin{tabular}{ccccccc}
\hline & \multicolumn{7}{c}{ Nilai Indeks Keseragaman (E) } \\
No & Tanggal & \multicolumn{2}{c}{ Atribut Rumpon } & \multicolumn{2}{c}{ Atribut Rumpon } & \multicolumn{2}{c}{ Atribut Rumpon } \\
& Daun Kelapa & \multicolumn{2}{c}{ Ranting Kayu } & \multicolumn{2}{c}{ Daun Kopi } \\
& ST I & ST II & ST I & ST II & ST I & ST II \\
\hline \multirow{2}{*}{ Nilai Indeks (E) } & & & & & & \\
& 0,292 & 0,268 & 0,950 & 0,244 & 0,122 & 0,097 \\
\hline
\end{tabular}

Nilai indek keseragaman tertingi pada rumpon Ranting Kayu Stasiun I dengan (E= $0,950)$ dan terendah terdapat di Staisun I $(E=$ 0,122) dan Stasiun II (E=0,097) pada rumpon Daun Kopi meskipun indek keseragaman diseluruh stasiun rendah.
Menurut Ferianita,

(2005)

Indeks keseragaman dapat dikatakan sebagai keseimbangan yaitu dengan menunjukan pola sebaran biota atau komposisi individu tiap spesies yang terdapat dalam suatu komunitas. Jika nilai indeks keseragaman relatif tinggi maka keberadaan setiap jenis biota di perairan dalam kondisi sama.

4. Kepadatan Populasi, Kepadatan Relatif dan Frekuensi Kehadiran

Kepadatan Populasi (KP), Kepadatan Relatif (KR\%), dan Frekuensi Kehadiran (FK). 
SEMAH : Journal Pengelolaan Sumberdaya Perairan VOL. 3 No. 1

April 2019

jenis Ikan Senggiring (Mystus nigriceps) sebesar 0,333 (individu).

Untuk Kepadatan Relatif (KR\%) paling tinggi terdapat pada ikan Tana (Barbodes binotatus) sebesar 20,3125 \%. Sedangkan Kepadatan Relatif (KR \%) terendah ditemukan pada ikan Semah (Tor soro) sebesar $6,250 \%$.

Selanjutnya untuk Frekuensi Kehadiran (FK \%) tertinggi atau Absolut di temukan pada 8 jenis ikan yaitu : Ikan Nalis (Labiobarbus lineatus), Senggiring, (Mystus nigreceps),

Sebarau

(Hampala macrolepidota) Bentulu (Barbichthys laevis) Semah (Tor soro) Tana (Barbodes binotatus) Puyou (Osteochilus waandersi) Kepyur (Barbodes lateristiga).

5. Jenis - Jenis Ikan Yang Tertangkap berdasarkan Atribut Rumpon Yang

\begin{tabular}{|c|c|c|c|c|c|c|c|c|}
\hline \multirow[t]{2}{*}{ No } & \multirow[t]{2}{*}{ Spesies } & \multicolumn{2}{|c|}{ Rumpon Daun Kelapa } & \multicolumn{2}{|c|}{$\begin{array}{c}\text { Rumpon Ranting } \\
\text { Kayu }\end{array}$} & \multicolumn{2}{|c|}{$\begin{array}{l}\text { Rumpon Daun } \\
\text { Kopi }\end{array}$} & \multirow{2}{*}{$\begin{array}{l}\text { Jumlah/ } \\
\text { Individu }\end{array}$} \\
\hline & & Stasiun I & Stasiun II & Stasiu & I Stasiun II & Stasi & un I Stasiun II & \\
\hline 1 & Labiobarbus lineatus & 2 & 1 & 3 & 2 & 1 & 2 & 11 \\
\hline 2 & Mystus nigreceps & 2 & 4 & 3 & 1 & - & - & 10 \\
\hline 3 & Hampala macrolipidota & 1 & - & 3 & 2 & - & - & 6 \\
\hline 4 & Barbichthys laevis & 1 & 3 & 1 & - & 1 & - & 6 \\
\hline 5 & Tor soro & - & - & 3 & 1 & - & - & 4 \\
\hline 6 & TBarbodes binotatus & 3 & - & 5 & 2 & 2 & 1 & 13 \\
\hline 7 & Osteochilus waandersii & 2 & 3 & 1 & - & 1 & - & 7 \\
\hline 8 & Barbodes lateristiga & - & - & 3 & 2 & - & 2 & 7 \\
\hline & Jumlah Total & & & & & & & 64 \\
\hline
\end{tabular}

\section{Berbeda}

Rumpon merupakan salah satu alat bantu untuk meningkatkan hasil tangkapan
ojs.umb-bungo.ac.id/index-php/SEMAHJPSP ISSN : 2580-0736

dimana mempunyai kontruksinya menyerupai pepohonan yang di pasang (ditanam) di suatau tempat di perairan yang berfungsi sebagai tempat berlindung, mencarai makan, memijah, dan berkumpulnya ikan. Ikan-ikan ini akan memikat ikan yang berukuran lebih besar untuk memakannya. Untuk melihat jumlah ikan yang tertangkap pada masing-masing atribut rumpon dapat disajikan pada tabel 4.5 berikut ini :

Dari tabel dapat dijelaskan bahwa jenis ikan yang tertangkap pada atribut Rumpon daun Kelapa di Stasiun I sebanyak enam jenis dengan jumlah individu sebanyak 11 ekor sedangkan pada Stasiun II terdapat 
SEMAH : Journal Pengelolaan Sumberdaya Perairan VOL. 3 No. 1

April 2019

terdapat 8 jenis ikan dengan jumlah individu 32 ekor. Berdasarkan tabel tersebut dapat dijelaskan bahwa pada Stasiun I terdapat 5 jenis ikan diantaranya pada Stasiun I dan Jenis ikan di Stasiun II, Ikan Nalis, Bentulu, Tana, Kepyur dan Puyou dengan jumlah individu sebanyak 10 individu. Sedangkan pada Stasiun II terdapat 6 jenis ikan diantaranya Nalis, Senggiring, Sebarau, Semahdan Tana dengan jumlah individu sebanyak 10 individu dan rumpon Atribut Ranting Kayu pada Stasiun I dan Stasiun II terdapat 4 dan 3 jenis ikan dengan jumlah individu 10 ekor. Berdasarkan tabel tersebut diatas dapat dijelaskan bahwa hasil tangkapan pada atribut rumpon Ranting Kayu pada Stasiun I terdapat 8 jenis ikan dengan jumlah individu sebanyak 22 sedangkan jumlah ikan yang tertangkap pada Stasiun II terdapat 5 jenis ikan dengan jumlah jumlah individu sebanyak 10 individu.

\section{KESIMPULAN DAN SARAN}

1. Kesimpulan

Berdasarkan hasil Penelitian yang telah dilakukan dapat ambil beberapa kesimpulan sebagai berikut:

1. Keanekaragaman jenis ikan yang tertinggi di temukan pada rumpon yang menggukan atribut ranting kayu yaitu sebanyak 32 ekor dengan indeks
ojs.umb-bungo.ac.id/index-php/SEMAHJPSP ISSN : 2580-0736

keanekaragaman sebesar 0,3281 dan indeks keseragaman sebesar 0,950 yang terdiri dari 8 jenis ikan di Stasiun I dan di Stasiun II 6 jenis ikan diantaranya : Ikan Nalis (Labiobarbus lineatus), Senggiring, (Mystus nigreceps), Sebarau (Hampala macrolepidota) Bentulu (Barbichthys laevis) Semah (Tor soro) Tana (Barbodes binotatus) Puyou (Osteochilus waandersii) Kepyur (Barbodes lateristiga).

2. Atribut Rumpon yang disukai oleh ikan yaitu menggunakan atribut rumpon ranting kayu dengan jumlah hasil tangkapan terbanyak dengan jumlah 8 jenis ikan pada Stasiun I dan pada Stasiun II terdapat 6 jenis dengan jumlah individu sebanyak 32 individu.

\section{Saran}

1. Untuk menı ikan yang lebil dalam penelitian lebih lanjut disarankan agar menggunakan atribut rumpon bahan yang lannya. Jumlah Stasiun yang lebih banyak dan jangka waktu yang lebih lama.

2. Perlunya dilakukan penelitian lebih lanjut di tempat yang 
SEMAH : Journal Pengelolaan Sumberdaya Perairan VOL. 3 No. 1

April 2019

berbeda tentang keanekaragaman jenis ikan yang tertangkap menggunakan atribut rumpon yang berbeda.

\section{DAFTAR PUSTAKA}

Arrington, D.A. and K.O. Winemiller. 2003. Organization and maintenance of biological diversity in neotropical floodplain rivers. In: Welcomme, R. and T. Petr. (ed.). Proceedings of the Second International Symposium on the Management of Large Riversfor Fisheries Volume II.FAO Regional Office for Asia and the Pacific, Bangkok, Thailand. RAP Publication 2004/17.

Besweni. 2009. Kebijakan Pengelolaan Rumpon Yang Berkelanjutan Di Barat Daya Perairan Pelabuhanratu. Disertasi. Sekolah Pascasarjan. Institut Pertanian Bogor. Bogor

Budiyono, 2011. Studi Hubungan Kualitas Air Dengan Keanekaragaman Jenis Ikan Di Sungai Batang Bungo Kabupaten Bungo. Http://budibungo.blogspot.com/2010 /06/keaneka-ragaman-jenis-ikan-disungai.html. diunduh Januari 2017.

Bengen, Dietriech G,2000.Sinopsis Ekosistem dan Sumberdaya Alam PesisirPusat Kajian Sumberdaya Pesisir dan Lautan-IPB,Bogor.

Boy R L and Smith B R. 1984. An Improved FAD Mooring Line Design for General use in Pasific Island Countries, SPC/Fishenes 15AVP.2. 77 p.

Buku Data Status Lingkungan Hidup Daerah Provinsi Jambi. 2014.
ojs.umb-bungo.ac.id/index-php/SEMAHJPSP

ISSN : 2580-0736

Diana. F, S. Mahjali, Edwarsyah dan A. Rozi, 2i upon Reefpiramit , stem Baru Biot: Irnal Ceureumen $\quad 1$ Agustus-Sept 11 23. Diunduh Mei 2017

Dinas Perikanan Propinsi Jambi. 1993. Studi identifikasi atau inventarisasi plasma nutfah perikanan perairan umum, Jambi. 119 hal.

DKP. 2007. Undang-undang No.27 Tahun $2007 \quad$ Tentang Pengelolaan Wilayah Pesisir dan Pulau-Pulau Kecil. Departemen Kelautan dan Perikanan. Jakarta.

Effendi, H. 2003. Telaah kualitas air bagi Pengelolaan Sumberdaya dan Lingkungan Perairan. Kanisius. Jogjakarta.

Efton. J. 2015. Pengaruh Perbedaan Mata Jaring Insang Tetap (Gillnet) Terhadap Hasil Tangkapan Ikan Di Sungai Menyabu Kabupaten Merangin Propinsi Jambi. Skripsi. Fakultas Perikanan. Universitas Muara Bungo. Bungo.

GOODING,R. M. 1965.Araftfor direct subsur-face observation atsea. Spec.Sci.Rept.Fish.U. S.Fish Wildl.Servo $517: 1-5$.

Gonawi G R. 2009. Habitat Struktur Komunitas Nekton Di Sungai Cihideung- Bogor Jawa Barat (Skripsi). Bogor : Institut Pertanian Bogor.

Fachrul, M. F. 2008. Metode Sampling Bioekologi. Ed ke-2. Jakarta. Penerbit Bumi Aksara. 
SEMAH : Journal Pengelolaan Sumberdaya Perairan VOL. 3 No. 1

April 2019

Ferianita, F.M., Herman H., L.C. Sitepu. 2005. Komunitas Fitoplankton

Sebagai Bio-Indikator Kualitas

Perairan Teluk Jakarta. Seminar

Nasional MIPA 2005. FMIPA-

Universitas Indonesia, 24-26

November 2005. Jakarta.

Hoek, E. 2009. Fundamental of Slope Design. Slope Stability Conference: Santiago, Chile.

Jamal.M. 2003. Studi Penggunaan Rumpon untuk Meningkatkan Produksi Hasil Tangkapan Gillnet dan bubu dasar yang dioperasikan di perairan Kabupaten Sinjai Sulawesi selatan. Lutjanus. JTPK.8.(2)

Jeujanan, B. 2008. Efektivitas Pemanfaatan Rumpon Dalam Operasi Penangkapan Ikan Di Perairan Maluku Tenggara. Disertasi. Sekolah Pascasarjan. Institut Pertanian Bogor. Bogor.

Jeujanan. B, Martasuganda. S, M. Fedi, A.Sondita, R. Yusfiandayani dan D. Monintja. 2014. Pengelolaan Rumpon Keberlanjutan Pada Dimensi Ekonomi Di Perairan Kepulauan Kei Kabupaten Maluku Tenggara. Jurnal Ilmu dan Teknologi Kelautan Tropis, Vol. 7, No. 2. Diunduh Mei 2017.

Jukri, M., Emiyarti dan Syamsul, K. 2013. Keanekaragaman Jenis Ikan di Sungai Lamunde Kecamatan Watubangga Kabupaten Kolaka Provinsi Sulawesi Tenggara. Jurnal Mina Laut Indonesia. 01. (01): 23-37.

Keng H. 1978. Orders and Families of Malayan Seed Plants. Synopsis of Orders and Families of Malayan Gymnosperm. Dicotyledons and
ojs.umb-bungo.ac.id/index-php/SEMAHJPSP

ISSN : 2580-0736

Monocotyledons.

Singapore

University Press. 